\title{
New media, new communicative genres and inclusive technology- mediated L2 pedagogy: A conversation with Steve Thorne
}

Victoria Antoniadou

Universitat Autònoma de Barcelona, Barcelona, Spain

(Article received 20 October 2011; final version received 9 November 2011)

Professor Steve Thorne is well-known for his work on second and foreign language development and Internet-mediated communicative activity. He is identified with the study of language use, communication dynamics and technology-mediated foreign, second, and plurilingual language learning, occurring within and outside of formal educational settings. His work draws on sociocultural and cultural-historical approaches to language development and he is particularly interested in multiplayer online gaming environments, the "cultures of use" of Internet communication tools, and intercultural communication. Professor Thorne is currently a faculty member in the Department of World Languages and Literatures at Portland State University in the United States and the Department of Applied Linguistics at the University of Groningen in the Netherlands. The following interview took place in April 2011 on the occasion of the EUROCALL CMC \& Teacher Education SIGs Annual Workshop in Barcelona, in which Professor Thorne was the keynote speaker.

INTERVIEWER: Based on your extensive research on language learning, what is your view on the defining features of second or foreign language learning? How could it be best described and what should language teachers look for to pinpoint development in the second language?

STEVE THORNE: Very good question. Second language learning fundamentally is the process of increasing your capacity to communicate with and interpret the world, so there are a number of ways in which one could look at that. For example, one can look at actual student communication across time, changes in complexity or greater capacity to express particular kinds of meanings, and the like. One can also look at development as a measure of moving from a heavy reliance on external resources, such as another person or dictionaries or online 
translators, to an increasing capacity for autonomy, self-regulation, and less reliance on such external resources.

INTERVIEWER: You have been focusing your research on Internet-mediated international collaboration in education. Based on your experience with this practice, could you elaborate on the fundamental aspects that make engaging learners in telecollaboration vital for language learning and development?

STEVE THORNE: Sure. One issue is that language learning involves a lot more than 'language' per se. Through online intercultural exchanges, we are also learning how to create and participate in different kinds of social relationships. This idea of developing relationships of significance and maintaining these relationships through the use of a new language is a very powerful way to reframe language learning as the development of resources for doing social life. In this sense, I think online intercultural interaction is a profound pedagogical approach that helps us rethink both the processes and the eventual goals of second language education.

INTERVIEWER: We could reasonably argue that the advent and wide distribution of communication tools in practically every area of social life have shifted the focus from teaching grammatical competence to developing intercultural communicative competence, language socialization and the ability to work with other people to construct knowledge. Explicit grammar instruction is often regarded as a practice of the past, belonging to prescriptive conceptualizations of language. Nevertheless, the fact remains that students do have to be able to succeed in formal state exams that assess writing and grammatical competence. What is your view on this matter? Does the promotion of language socialization and multiliteracy competences in online settings contradict grammar instruction? Does it make grammatical competence a less important skill to aim for?

STEVE THORNE: Yes, this is an important issue. Of course high-stakes exams are very important. Students need to succeed in these high-stakes exams to move forward with their education or in other professional arenas. We have to help students do that so that they can be successful. On the other hand, I think that many of these high-stakes testing environments and 
restrictive understandings of 'correct' grammar are not particularly useful for language development or for promoting language learning. So, our job as educators, then, is to do a couple of things. We need to maintain an instrumental focus where we help students prepare for these high-stakes testing environments, but on the other hand, we also want to emphasize use value and integrational motivation that comes from creating opportunities for students to be meaningful communicators in a foreign language. This latter process may diverge significantly from formal registers of language use and this may be particularly the case in Internet-mediated environments. Developing a viable and fulfilling presentation-of-self in a new language is at the heart of the learning education project.

INTERVIEWER: Let's talk a bit about the conflict, if I may call it that, between grammar-based and communication-based language instruction because the view that you know a language when you know the grammar of that language is quite prevailing. In your experience with Internet-mediated environments, how do you deal with concerns related to the dichotomy between attaining a good level of grammar or formal writing skills and acquiring good communicative skills? Could technology-mediated communicative environments serve the goal of learning grammar?

STEVE THORNE: There are a couple of issues here. First of all, and this is meant to be an intentionally provocative statement, grammar doesn't exist in any practical sense. What we typically refer to as grammar is better understood as observable, recurrent and malleable patterns of language use. An entailment to this view is that different genres and different kinds of communicative engagement are structured or patterned in different ways. As I mentioned in the discussion we had just prior, in many ways we teach only a couple of generally very formal genres of language in instructional contexts. We teach formal writing and we teach relatively prescriptive approaches to verbal communication. But in the contemporary era, there are lots of new and social media that have given rise to new genres of communicative activity that are typically not represented in formal foreign language instruction. I think that we all really need to think about expanding the kinds of genres that we teach. This is why colleagues (for example Jon Reinhardt) and I have developed the idea of bridging activities as a structured pedagogical method for being more inclusive of linguistic varieties that are 
emerging from communication in new media. If you want to focus narrowly on formal accuracy, of course technology can be very useful. For example, you could have students engage in both conventional writing and editorial processes using a wiki or other universal write-access environment, which could mirror 'real-world' editorial processes and outcomes associated with newspaper and print publishing. Class-based writing assignments could be structured for actual publication, for example publishing essays to Wikipedia so that students have a real world goal for their work. Uses of technology and new media can involve both formal registers of language as well as exploration of digital vernaculars and phatic forms of communication that might diverse considerably from written language norms. So yes, in my view, technology can support many language learning activities.

INTERVIEWER: But quite often the students themselves, especially the older ones, expect formal grammar instruction.

STEVE THORNE: Yes, that is often true. It is about frames of expectation, the presumption that formal grammar instruction is what happens in school. Before a student arrives at university, she has at least 12 years of sitting in classrooms with teachers telling her this is precisely what to learn and this is the way you need to learn it, perhaps by using a grammatical rule to generate an accurate syntactic string. But of course actual communication doesn't work this way. Rules are not particularly useful for real-time language processing and research shows that they aren't useful for language description either. If you take a given grammatical rule, what is the first thing you are taught? All the exceptions to the rule! The more texts you look at, the fewer rules there are that broadly apply or are useful. If you are really looking for sophisticated and theoretical approaches to language learning and development, I think concept-based grammar and cognitive linguistics are much more productive. Pragmatics is also a relevant approach that focuses on the social implications of particular forms of talk and stresses the need to design certain uses of language for certain purposes and audiences. In my opinion, this is the kind of sensitivity and awareness you need to develop as a language user. To give a few examples, if you are writing a cover letter for a job that you care about, of course it needs to be in a cover letter genre and it needs to be spelled and punctuated appropriately for that purpose and with a specific audience in mind. 
But if you are engaging in synchronous chat or text messaging with friends, the conventions are utterly different. If you are in a face-to-face environment such as presenting an academic talk at a conference, there is a relatively clear standard for contextually appropriate communication. In contrast, if you are with friends in a night club or sitting across the dinner table from your grandparents, you would need to adhere to different styles of communication that are responsive to context, purpose, audience, maybe channel or mode if you are using technology-mediated communication. To my eye, the key thing about language education is to cultivate in learners the power to ascertain, understand and engage in communicative activity that is relevant and successful given the context, the purpose, and the intended audience.

INTERVIEWER: It all depends on the context.

STEVE THORNE: Yes, exactly, and it also depends on the social action that you want to carry out. For example, one of the most powerful tools in communication is knowing when to flout or intentionally not adhere to expected norms or frames. That is how many jokes work and that is what can make people clever and interesting to talk to, when they know when and how to create a potential frame of reference and then shift it or break it for rhetorical effect. And of course, when the situation calls for it, you need to be extremely formal and very precise with your elocution and with spelling and grammar, especially in written communication. This is the case in school contexts, in high-stakes testing contexts, in formal academic and professional contexts, and the like.

However, it isn't the case that formally punctuated and spelled language is always the appropriate kind of language to use. There are many other communicative situations that require an entirely different presentation of self and which require different genres of communication. And again, to be clear, if you are a student in a classroom situation, you will need to know the formal or power genres of language. I think this is a fairly straightforward point. The real thing that I care about in language education, however, is to nurture the development of critical language awareness so that students will know when to use what kind of language, for what sorts of purposes or social actions, and with which audience. That is what I really want to push in foreign language education since we don't know what sorts of communicative situations are coming, even in the near future. Five years from now, who 
knows what kinds of new genres of communication will emerge? Currently it is Twitter, Facebook and social networking sites, synchronous text messaging, communication in online gaming environments, and the like. But in ten years, it is difficult to predict what the new communication tools will be and what the genres of communicative activity that make one an insider and successful in these settings will look like. Since we, as foreign language educators, can't know this, our goal should be to prepare students not just to succeed with traditional language genres but also to prepare them to be lifelong learners and lifelong communicators in ways that are powerful and relevant and that will allow them to contribute to both society and whatever local context or engagement that they are involved in, be it professional, recreational, social, or what have you. In essence, the goal is to become a powerful communicator, and these competencies don't stop with mastery of formal and standard uses of language alone.

INTERVIEWER: Is the bridging activities model, a pedagogical approach oriented toward enhancing language awareness and contrastive analysis of new media and traditional genres of language (as is explained in the articles Thorne \& Reinhardt, 2008; Reinhardt \& Thorne, 2011), designed with a particular age-group in mind or could it be implemented for advancing writing skills in lower-proficiency levels, for example, where writing skills are minimally developed?

STEVE THORNE: Definitely. You always have to start somewhere. The bridging activities model acknowledges that we do a couple of things pretty well in traditional academic contexts, such as focusing on formal accuracy and focusing on long-standing traditions that inform what good writing is supposed to be. We need to also be inclusive of other genres of communication and that is where the bridging activities model might be useful. The idea is fundamentally that you can engage in contrastive analysis so if you are learning one thing in school, traditional school-based literacy for example, that you can compare and contrast some other communicative activity in the world with the kinds of language that you are learning in school. What are the differences? You might find, of course, that there is a very large Venn diagram overlap where in fact much of the language might seem quite similar across these different contexts, but there are particular words or phrases or patterns or contractions or 
neologisms that are happening in one environment that might be specific or different, so focus on those and look at the kinds of social actions that are most relevant to the online setting that your students might be interested in, then look at how those social actions are realized at the level of morphosyntax, collocational patterns, and style. The point is to begin to gain the ability to figure out the recurrent patterns and resources that comprise the commonly used linguistic resources that make up a speech community or that comprise some aspect of communicative practice that is high-frequency and important to your students.

INTERVIEWER: $\quad$ So could we say that the implication of all this is to create multiple and inclusive environments both online and offline in order to advance the learning of these types of competences?

STEVE THORNE: Yes, absolutely, and I will talk about this later today in my keynote presentation. I think we still need to devote 80 or $90 \%$ of our time to the formal standard expectations of language use because students need it for tests; they need it for producing scholarship and participation in formal academic literacy and workplace communities. That is still very important. But this is not to say that we shouldn't attend to a loftier and more important goal, which extends beyond simply being really good at academic literacy or formal uses of language and includes becoming a powerful communicator in a wide variety of settings. My friend Paul Prior has discussed a similar idea, that of developing a greater capacity for "semiotic agility." I really like this formulation. Developing semiotic agility, across a wide range of communicative contexts and communities, is a higher order enterprise than simple mastery of the technical dimensions of standard forms of language.

INTERVIEWER: How about multiplayer online gaming? Could we safely argue for a reliable environment for language learning?

STEVE THORNE: Firstly, let me say that this is an empirical question. There is a quite a lot of negative popular press related to online gaming, saying things like gamers are lazy, in search of an immediate gratification, and the like. So, if language researchers and educators think gaming is not interesting and that there is not enough linguistic complexity in these 
settings to make them good for language learning, prove it. Do the analysis. Some critics have said that online gaming involves just a bunch of small talk and phatic communication, right? Let's look at naturally occurring conversational interaction between two people like we are doing now in this interview. Is it interesting? Is it dynamic? Is it complex? What is going on here? What are all the communicative resources being utilized and what is the cognitive load of the interactional style, format, and substantive content comprising this interview setting? Moving back to technology, there are online games that are relatively straight-forward or simple and others that are very complex. This is also the case with social media like facebook; wall posts may not be that complex linguistically, just a set of short phrasal utterances that are linked, but in many other cases, there might be something much more interesting going on. This would depend on the people involved, it would depend on the speech community. Online games and social media don't exist in isolation and in fact, I don't think it is very helpful to think about gaming as a bounded arena. To give you only one example, I am doing a project now looking at the linguistic ecology of online gaming environments and I have empirically shown that there are multiple types of both in-game textual and communicative activity and also attendant discourses associated with games such as 'strategy websites'. These 'strategy websites' show the use of formal scientific method, problem solving, and collaborative knowledge construction. There are also fan fiction websites based on online games, which basically take the form of online novels, some of which are tens of thousands of words long, basically the same length and similar in linguistic and stylistic complexity as traditional print books. I think that we need to look at these phenomena with a more expansive view. It is very common to think that gaming and social media are simple, substantively uninteresting, and if you believe the critics, that social media and online gaming are the death of critical thinking and complex language use. Again, I say -- prove it! What I think a serious and empirical examination will show is that online gaming and social media are similar to many other communication contexts - some environments might not be particularly interesting or useful for language learning, while in other settings, there may be a lot of complexity and sophisticated thinking going on. And independent of the complexity or how superficial or deep and thought-provoking online interaction may or may not be, the people involved care about what is happening or they wouldn't be wasting their time doing it. People are engaging in social media and online gaming in large numbers, so we, as researchers and language 
educators, need to know what is going on in those settings because participants are taking these activities very seriously. So, minimally on a descriptive level, we need to know what is happening and then we can think about the relationship between action and interaction in these environments as they may pertain to second language development.

INTERVIEWER: You talk about social virtualities. Do you see these social virtualities like Second Life etc. as the next step to language learning, implemented as mediums in mainstream language teaching and learning?

STEVE THORNE: Yes, I think that virtually rendered three-dimensional worlds or online spaces are already important in education. Online social virtualities is one of the contemporary but also near future scenarios for technology-mediated education, perhaps particularly for distance learning and online intercultural exchanges. People are developing simulations and scenario-based approaches that address communication contexts that are difficult to model in an effective way in a classroom, but you can do it quite readily using an avatar-driven threedimensional environment. The work on Spanish (as a foreign) language pragmatics that Julie Sykes has done is a good example. In fact, Jon Reinhardt and Julie Sykes are co-directing a gaming project called Games To Teach that addresses foreign language learning ${ }^{1}$. They look at a variety of online gaming and online social virtuality spaces and then propose ways in which action and interaction in these settings might be quite useful for language learning. So I definitely think that it is a contemporarily available and certainly a near-future growth industry in the area of computer-assisted language learning.

INTERVIEWER: You have been involved with sociocultural theory and Cultural-Historical Activity Theory. Could you describe a bit your trajectory from the point you first got involved with sociocultural theory and the Vygotskian ideas up to now and how your ways of thinking have evolved?

STEVE THORNE: The key thing about the cultural-historical approach for me was, in the 1990s, being exposed to the notion of mediation. In the context of technology, computerassisted language learning or otherwise, this key concept of mediation is important because 
mediation is not simply a neutral or transparent way to get something done. It actually is a process that makes certain things more visible and enables new morphologies of action. The other key aspect of my interest in this area is looking at culturally-organized systems of activity as a framework or a unit of analysis that can help us to understand learning and teaching environments in a more profound way. I think cultural-historical activity theory is very useful and very important as both a research framework but also as an orientation for developing interventions and that it is something I know Yrjö Engeström, Michael Cole, James Wertsch, Peter Sawchuk, and others are doing in the area of education and workplace settings. In essence, cultural-historical activity theory is a framework for intervening and improving things in some demonstrable way. My sense is that cultural-historical activity theory is increasing in its visibility in both research and in applied interventionist areas and I think it is a powerful and highly relevant framework for both research and transformationoriented projects.

INTERVIEWER: And, one last question, is there any advice or recommendation you would like to give to new researchers working with this theory?

STEVE THORNE: I would suggest reading a lot of case studies and looking at how people are using the theory in the area you are interested in. I think it is probably a good idea to go back and read classic pieces in the literature from Vygotsky himself as well as Luria, Leont'ev, Michael Cole’s 1996 book that reviews cultural-historical approaches to development, Engeström's work is always stimulating and highly creative, and there are a number of texts that focus specifically on teaching and learning contexts, for example a recent volume edited by Annalisa Sannino, Chris Gutierrez, and Harry Daniels that looks at teaching and learning that reviews research in these areas. And there is my work with Jim Lantolf and others that focuses on second language development and teaching. So yes, I think that looking at research and looking at existing studies can be a very helpful way to enter this research and intervention community that is informed by cultural-historical activity theory.

INTERVIEWER: I want to thank you very much for all your time and invaluable insights you have shared with us during this interview. 
STEVE THORNE: It was my pleasure, thank you.

${ }^{1}$ http://games2teach.wordpress.com/

Author References:

Victoria Antoniadou is a doctoral student at the Departament de la Didàctica de la Llengua de la Literatura i de les Ciències Socials at the Universitat Autònoma de Barcelona. Her research interests draw upon the sociocultural-historical line of thought regarding learning and development through which she explores teacher learning trajectories over lengthy periods of time. The study incorporates the investigation of teacher learning in the making, process and outcomes, as it unfolds across a blended configuration of online and offline spheres of participation, social interaction and manifold resources.

Email: Victoria.Antoniadou@e-campus.uab.cat 